\title{
Importância do ambiente físico e microclima na ambiência urbana
}

Importance of physical environment and microclimate in urban environment

Importancia del entorno físico y el microclima en el ambiente urbano

\author{
Evanisa Fátima Reginato Quevedo Melo \\ Professora Doutora, UPF, Brasil \\ evanisa@upf.br
}

Rodrigo Henryque Reginato Quevedo Melo

Mestrando PPG Engenharia Civil, IMED, Brasil rodrigohquevedo@gmail.com

Ricardo Henryque Reginato Quevedo Melo Professor Mestre, IMED/UFRGS, Brasil ricardohquevedo@gmail.com 


\section{RESUMO}

A análise realizada trata sobre a qualidade do ambiente físico e climático da Praça Antonino Xavier, localizada na cidade Passo Fundo/RS. O estudo, tem como objetivo evidenciar a importância da utilização de vegetações no meio urbano, ressaltando seus benefícios para a redução da amplitude térmica, filtragem do ar - através da retenção de partículas sólidas -, redução da poluição sonora, captura de gás carbônico e liberação de oxigênio, e melhor ambiência urbana. Além disso, busca demonstrar as mudanças climáticas que ocorreram em diferentes pontos da área e ressaltar as opiniões dos seus usuários quanto ao mobiliário existente e a qualidade do local. Para desenvolvê-lo, realizou-se levantamento de dados, no mês de setembro de 2018, contendo informações sobre o ambiente físico e climático da área. A praça foi dividia em 11 pontos de análise, partindo dos pontos situados nas extremidades do terreno em direção ao eixo central, obtendo-se, assim, pontos localizados em diferentes cotas e distâncias. Foram realizadas medições das variáveis climáticas e aplicados questionários aos usuários da praça, contendo perguntas de conhecimentos gerais sobre o local e a sua qualidade. Os dados foram comparados para verificar se as alterações influenciaram na qualidade de vida do local. Constatou-se que as vegetações são de extrema importância para a regularização climatológica urbana. Além disso, percebe-se que o entorno influencia diretamente nas condições ambientais de determinadas áreas, podendo fazer com que o local se torne inapropriado para uso em algumas épocas do ano reforçando a importância das áreas verdes no microclima urbano.

PALAVRAS-CHAVE: Microclima. Vegetação urbana. Conforto ambiental.

\section{ABSTRACT}

The analysis is about the quality of the physical and climatic environment of Praça Antonino Xavier, located in the city Passo Fundo / RS. The aim of the study is to highlight the importance of using vegetation in urban areas, highlighting its benefits for the reduction of thermal amplitude, air filtration - through the retention of solid particles - reduction of noise pollution, carbon dioxide capture and release. oxygen, and better urban ambience. In addition, it seeks to demonstrate the climate changes that occurred in different parts of the area and to highlight the opinions of its users regarding the existing furniture and the quality of the place. To develop it, a data survey was conducted in September 2018, containing information on the physical and climatic environment of the area. The square was divided into 11 points of analysis, starting from the points located at the ends of the terrain towards the central axis, thus obtaining points located at different dimensions and distances. Climatic variables were measured, and questionnaires were applied to the users of the square, containing general knowledge questions about the place and its quality. The data were compared to verify if the changes influenced the quality of life of the place. Vegetations were found to be extremely important for urban climatological regularization. In addition, it is noticed that the environment directly influences the environmental conditions of certain areas, which may make the place unsuitable for use at sometimes of the year reinforcing the importance of green areas in the urban microclimate.

KEYWORDS: Microclimate. Urban vegetation. Environmental comfort.

\section{RESUMEN}

El análisis trata sobre la calidad del entorno físico y climático de la plaza Antonino Xavier, ubicada en la ciudad de Passo Fundo / RS. El objetivo del estudio es resaltar la importancia del uso de la vegetación en las zonas urbanas, destacando sus beneficios para la reducción de la amplitud térmica, la filtración del aire, a través de la retención de partículas sólidas, la reducción de la contaminación acústica, la captura y la liberación de dióxido de carbono. oxígeno y mejor ambiente urbano. Además, busca demostrar el cambio climático en diferentes partes de la región y resaltar las opiniones de sus usuarios sobre los muebles existentes y la calidad del lugar. Para desarrollarlo, se realizó una encuesta de datos en septiembre de 2018, que contenía información sobre el entorno físico y climático de la zona. El cuadrado se dividió en 11 puntos de análisis, comenzando desde los puntos ubicados en los extremos del terreno hacia el eje central, obteniendo puntos ubicados en diferentes dimensiones y distancias. Se midieron las variables climáticas y se aplicaron cuestionarios a los usuarios del cuadrado, que contenían preguntas generales de conocimiento sobre el lugar y su calidad. Los datos se compararon para verificar si las alteraciones influyeron en la calidad de vida del lugar. Se ha encontrado que las vegetaciones son extremadamente importantes para la regularización climatológica urbana. Además, está claro que el medio ambiente influye directamente en las condiciones ambientales de ciertas áreas, lo que puede hacer que el sitio sea inadecuado para su uso en algunas épocas del año, lo que refuerza la importancia de las áreas verdes en el microclima urbano.

PALABRAS CLAVE: Microclima. Vegetación urbana. Confort ambiental. 


\section{INTRODUÇÃO}

Ao longo dos anos a população urbana aumentou significativamente, onde, segundo Camarano (1999) do Instituto de Pesquisa Econômica Aplicada do Brasil, em termos nacionais a intensidade do movimento de deslocamento da população rural para as cidades parece ter mantido a sua intensidade nas últimas décadas. Devido este movimento, as áreas urbanas sofreram um crescimento significativo, onde, associado a aglomeração populacional, o crescimento desenfreado e sem planejamento resultou no aumento da degradação ambiental.

Sabe-se que a cidade modifica o clima através das alterações em sua superfície, produzindo aumento de energia térmica, modificações no fluxo de vento, diminuição da umidade relativa e da infiltração da água das chuvas, em função do aumento da superfície impermeável formada pela pavimentação e área construída. Isso ocorre porque a substituição dos materiais naturais pelos materiais urbanos provoca mudanças nos processos de absorção, transmissão e reflexão, bem como, nas características da atmosfera local (DUARTE, 2000). O conjunto destes fatores, juntamente com o calor produzido pelo homem, menores velocidades do vento e poluição do ar, o que modifica o clima local, resultam na formação de ilhas de calor (GARTLAND, 2008). Como define Romero (2000), "os fatores climáticos locais são aqueles fatores que condicionam, determinam e dão origem ao microclima, isto é, ao clima que se verifica num ponto restrito (de uma cidade, de um bairro ou de uma rua etc.)". A autora destaca que a presença de vegetação contribui significativamente na melhora dos microclimas encontrados no centro das cidades, pois além do sombreamento, o processo de fotossíntese aumenta a umidificação do ar.

Lombardo (1985), afirma que uma ilha de calor urbana pode ser atribuída aos seguintes fatores: efeitos da transformação de energia no interior da cidade, com formas específicas (estruturas verticais artificialmente criadas), cores e materiais de construção (condutibilidade), redução do resfriamento causado pela diminuição da evaporação (poucas áreas verdes, transporte de água da chuva através de canalização) e produção de energia antropogênica, por meio da emissão de calor pelas indústrias, trânsito e habitações.

De acordo com a Agência de Proteção Ambiental Norte-americana EPA (Environmental Protection Agency, 2008), ilha de calor urbana (ICU) é uma alteração do clima que pode ser observada nas cidades caracterizando-se por áreas urbanas mais aquecidas que a vizinhança menos urbanizada e rural. Este efeito também pode ser verificado na superfície e atmosfera urbana (STEWART e OKE, 2012). Assim diversos estudos vêm sendo realizado na área de análise microclimática destacando-se as contribuições de Oke (1987), Santamouris (2013) e Romero (2015) evidenciando a análise do desenho urbano.

Diversas características podem ser associadas a ilhas de calor, porém Amorim (2005), destaca que o parâmetro mais importante que caracteriza a ilha de calor é sua intensidade ou magnitude, o que geralmente evolui mediante a diferença máxima observada, em um momento determinado, entre a temperatura de um ponto da cidade, densamente construído, e outro em seu entorno ou no ambiente rural.

A área de estudo do presente artigo é a Praça Antonino Xavier, também conhecida como Praça do Hospital da Cidade, a qual fica localizada no Bairro Centro, no município de Passo Fundo, norte gaúcho. Construída com o objetivo de criar uma área de lazer e contemplação, no local há a presença de playground infantil, quadra, túneis literários, academia urbana, quiosque de leitura, pista para caminhada e sanitários. Destaca-se a escolha desta praça pois a mesma 
encontra-se próxima de um importante hospital do município, o que gera um maior fluxo de pessoas na região e consequentemente uma demanda maior por espaços públicos.

As áreas verdes urbanas foram evoluindo ao longo do tempo, sendo, inicialmente, representadas pelos jardins com o objetivo de agradar a visão e o olfato, onde em grande parte dos casos estavam ligados a cultura e a religião. Com a evolução deste conceito, as áreas verdes dentro do espaço urbano passaram a ganhar reconhecimento e importância como uma solução quanto à requalificação do ambiente (SCHUTZER, 2012). Dentro do planejamento urbano, essa consciência e percepção ambiental são materializadas na concepção de praças e parques públicos.

Destaca-se que as praças são elementos fundamentais na urbanização, pois, além de fornecerem atividades recreativas e de lazer para a população, atuam como maciços vegetativos, criando uma área que auxilia na melhoria climática da região. Ao citar Duarte (2000), Franco et al. (2012) afirma que "o uso da vegetação e do sombreamento permite a criação de espaços ao ar livre com um microclima diferenciado, aumentando a umidade do ar, reduzindo ganhos térmicos pela radiação solar e diminuindo a temperatura do ar" (Franco et al, 2012 p. 2275). De acordo com Gehl (2011), quando o ambiente exterior é de boa qualidade, as atividades que nele ocorrem tendem a durar mais e, naturalmente, o ambiente torna-se mais convidativo. Dentro do estudo do urbanismo, as praças se destacam e caracterizam-se por quebrar uma sequência de quadras densamente edificadas e que, por sua vez, tomam o papel de tornar os centros urbanos mais dinâmicos e interativos, assumindo importância na vida social da população.

Nesse contexto as pesquisas sobre sustentabilidade urbana apontam a arquitetura bioclimática como um viés fundamental no planejamento, no conforto ambiental e na qualidade de vida das populações nos centros urbanos (FRANCO et al., 2012; MELO, et al., 2017). Desta forma, percebe-se a importância de incorporar a vegetação e os diversos componentes da natureza aos espaços urbanizados, para minimizar os impactos ambientais decorrentes do processo de urbanização, colaborando com a ambiência e a sustentabilidade urbana.

O objetivo da pesquisa é verificar a qualidade do ambiente físico e climatológico da praça Antonino Xavier na cidade de Passo Fundo/RS, considerando a sustentabilidade ambiental no desenho urbano e a influência climática em seu entorno. Além de avaliar a percepção do espaço pelos usuários.

\section{MATERIAIS E MÉTODOS}

Para o desenvolvimento desta pesquisa, foi selecionada uma praça na cidade de Passo Fundo, RS, sendo a Praça Antonino Xavier, a qual foi dividida em 11 pontos de análise, definidos de forma que abrangessem uniformemente a área, locados partindo das extremidades do terreno em direção ao centro, conforme a Figura 1. As medições ocorreram durante o dia 19 de setembro de 2018, no turno da manhã, com a utilização do aparelho medidor multifunções HMM-511A, da HOMIS. Foram recolhidos dados de análise, como temperatura, umidade do ar, luminosidade, nível de ruído e velocidade do vento, posteriormente, analisados no software de geoprocessamento ArcGIS. Em seguida, realizou-se o levantamento quantitativo da vegetação existente na área, assim como das espécies encontradas no local. Ainda foram realizadas 
análises solares no software Revit, com o objetivo de estudar a influência do entorno no sombreamento da praça.

Figura 1: Pontos de análise climática.

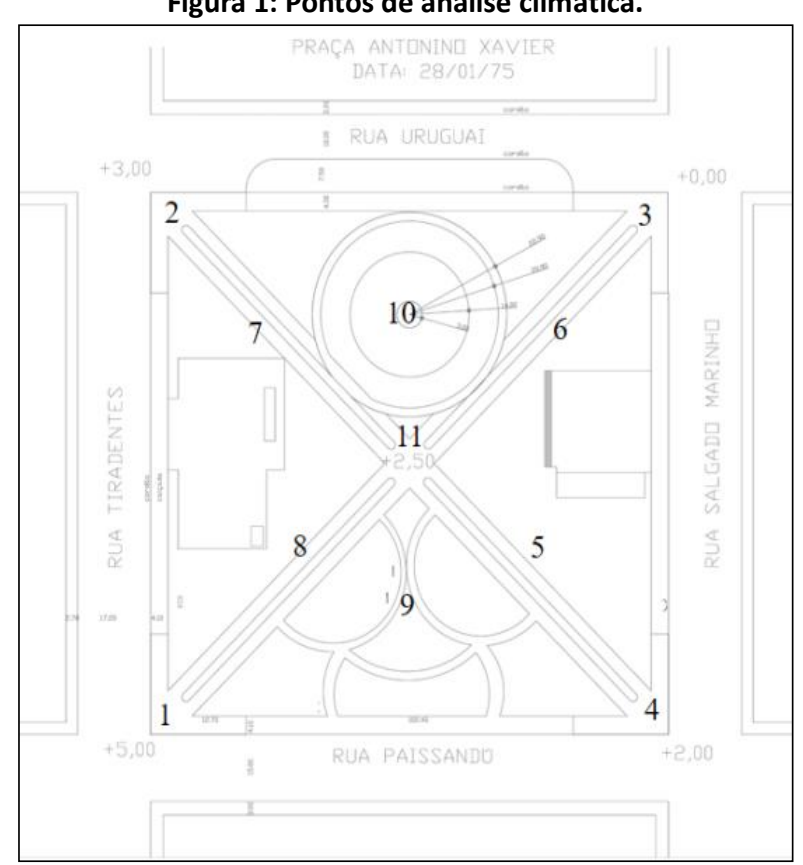

Fonte: AUTORES, 2019.

Além das análises físicas e climatológicas, foram aplicados questionários para obter a percepção dos usuários, que frequentam e utilizam o espaço que a praça proporciona para desenvolver diversas atividades, tanto de lazer, esporte ou cultural.

Assim foram aplicados questionários estruturados com 50 usuários da praça, que continham dados pessoais do entrevistado, como nome, a idade e a cidade onde reside, e de sua relação com a praça, como a denominação do local; a distância dela para o local onde reside; o horário que costuma frequentar a área; a frequência na semana com que transita pela praça; tempo de permanência; os locais e equipamentos mais utilizados; se a pessoa considera a praça com um visual agradável; condições de manutenção do local; se a praça possui coleta de lixo, um bom número de lixeiras, acessibilidade e placas informativas sobre a vegetação; quais os motivos que o levam a frequentar a praça; se apresenta recantos para ficar, cores, vegetação, sombra, luminárias e calçamento suficientes. Os dados foram sistematizados para análise em gráficos. Conforme ressalta Pinheiro e Günter (2008), o questionário é o instrumento mais utilizado para medir a satisfação dos usuários, uma vez que é relativamente rápida sua aplicação.

\section{RESULTADOS E DISCUSSÃO}

A praça analisada encontra-se em frente ao Hospital da Cidade, no município de Passo Fundo Rio Grande do Sul. Esse fato é de extrema importância, pois, em decorrência disso, a praça tornase bastante movimentada durante o dia, já que muitos dos seus usuários são pessoas que aguardam atendimento ou estão acompanhando enfermos internados no centro de saúde. 0 espaço público em questão é delimitado pelas Ruas Uruguai, Tiradentes, Paissandú e Saldanha Marinho. 
De acordo com Melo, Melo e Melo (2017, p.114), a arquitetura bioclimática considera, em seu estudo, a trajetória do sol, as correntes dos ventos e os microclimas criados pela vegetação, ou seja, durante uma análise do microclima é importante considerar esses elementos. Por isso, a pesquisa contou com o estudo da trajetória solar, a fim de discutir a influência do entorno no sombreamento da área da praça, relacionando-a com o diagnóstico dos microclimas desenvolvidos pela vegetação.

O entorno da praça é composto por uma edificação de caráter institucional, enquanto o restante das edificações é de uso comercial e residencial. Conforme a Figura 2, nota-se a existência de um edifício com maior altura em relação aos outros, porém, a interferência deste no sombreamento da região é somente na esquina, entre as ruas Salgado Marinho e rua Uruguai, logo, não interfere significativamente na praça. Realizou-se o estudo solar da influência das edificações do entorno na área da praça, do dia 19 de setembro de 2018, no horário das 10h00min, com a utilização do Software Revit (Figura 2). Com isso, observou-se que as edificações não interferem no terreno, fazendo com que a praça receba insolação direta.

Figura 2: Estudo solar: 19 de setembro, turno da manhã.

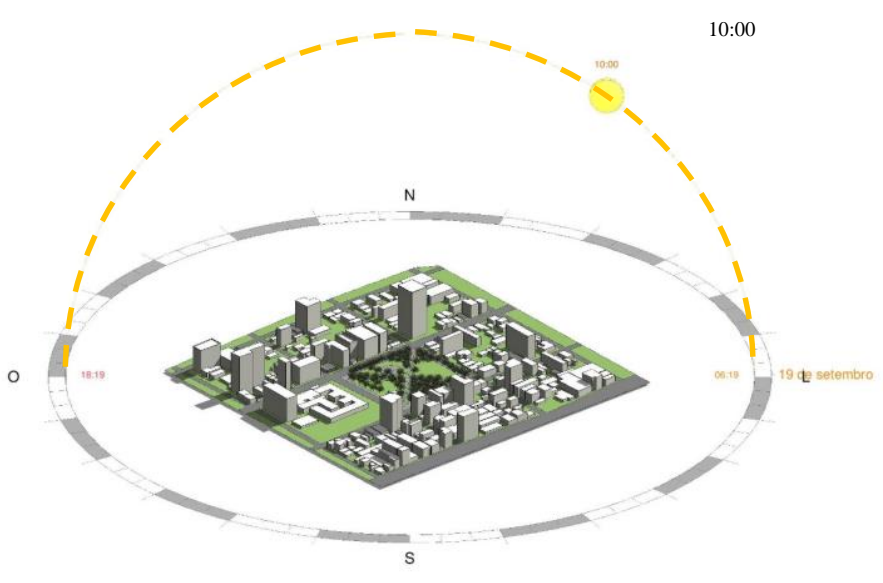

Fonte: AUTORES, 2019.

Já no turno da tarde, a simulação foi realizada às $15 \mathrm{~h} 00 \mathrm{mim}$ no mesmo dia. Com esta análise, percebeu-se que o sombreamento ocorre na rua Uruguai, fazendo com que o passeio de pedestres e a via dos veículos fique com sombra durante grande parte do período da tarde (Figura 3).

Outra análise utilizando-se o mesmo software foi realizada na condição em que mais há sombra dos edifícios do entorno sobre a praça, no dia 21 de junho às 17h00mim (Figuras 4). Considerando o horário selecionado, observou-se que neste horário alguns prédios interferem, no sombreamento da praça. Destaca-se o sombreamento da área às $17 \mathrm{~h} 00 \mathrm{mim}$. Nela nota-se, portanto, que praticamente toda a praça aparece sombreada, tornando o local úmido e frio. Considerando-se o uso da praça na estação do verão, isso traz um alívio térmico na área, mas se considerar o seu uso durante o inverno, esse horário torna a praça mais difícil para uma longa permanência. 
Figura 3: Estudo solar: 19 de setembro, turno da tarde.

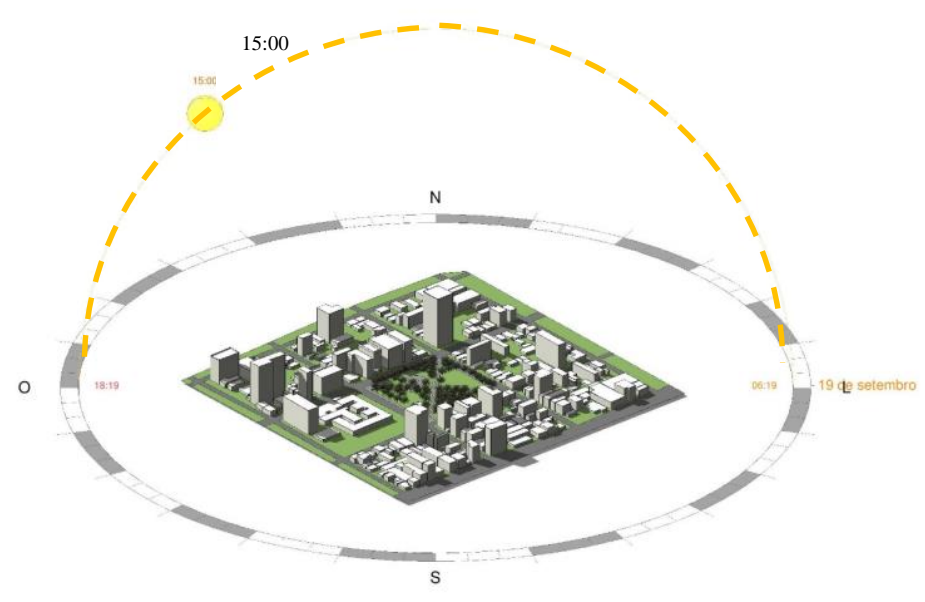

Fonte: AUTORES, 2019.

Figura 4: Estudo solar: 21 de junho as 17 horas.

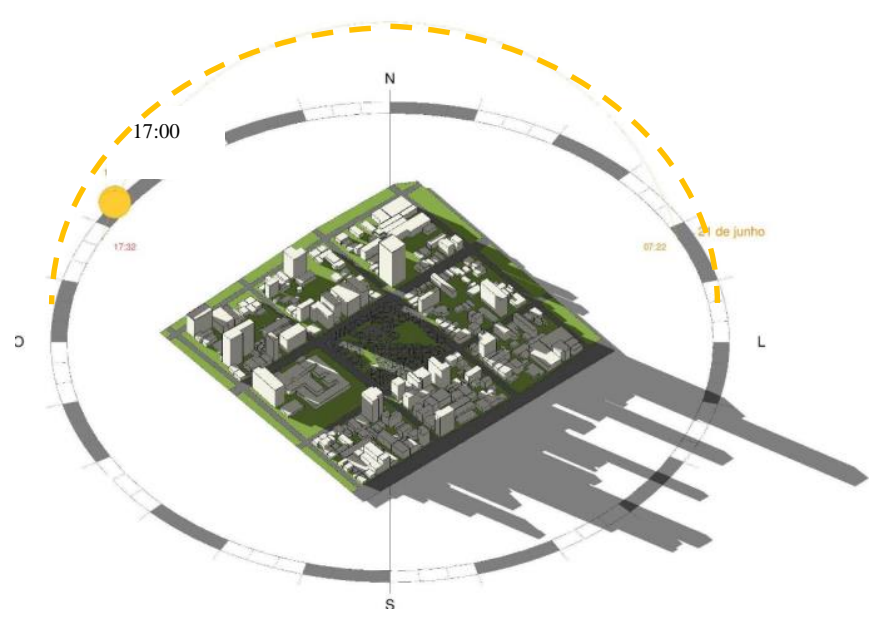

Fonte: AUTORES, 2019

Com o levantamento de dados realizado no dia 19 de setembro com o equipamento multifunções, contatou-se que as zonas climatológicas com maior índice de temperaturas ficam localizada em três pontos (Figura 5). O primeiro ponto encontra-se no eixo central da pista de caminhada, onde não existem vegetações e o piso é de concreto, sem área de permeabilidade, criando assim uma ilha de calor; já o segundo localiza-se no canto superior direito em uma das esquinas da praça com influência das vias de rolamento pavimentadas em asfalto, acumulando calor; e o centro do terceiro ponto está em uma área aberta, com pouca vegetação. Os resultados demonstram uma ilha de calor concordando com afirmações de Melo, Melo e Melo (2017) em que a tipologia das construções, morfologia e o fluxo intenso nas vias asfaltadas interferem no incremento de calor, criando um microclima, evidenciando a influência do entorno. Ainda pode-se demonstrar que a arborização urbana propicia temperaturas mais agradáveis e melhoria no conforto ambiental e na ambiência. 
Figura 5: Análise térmica das medições de setembro, 2018 na Praça Antonino Xavier.

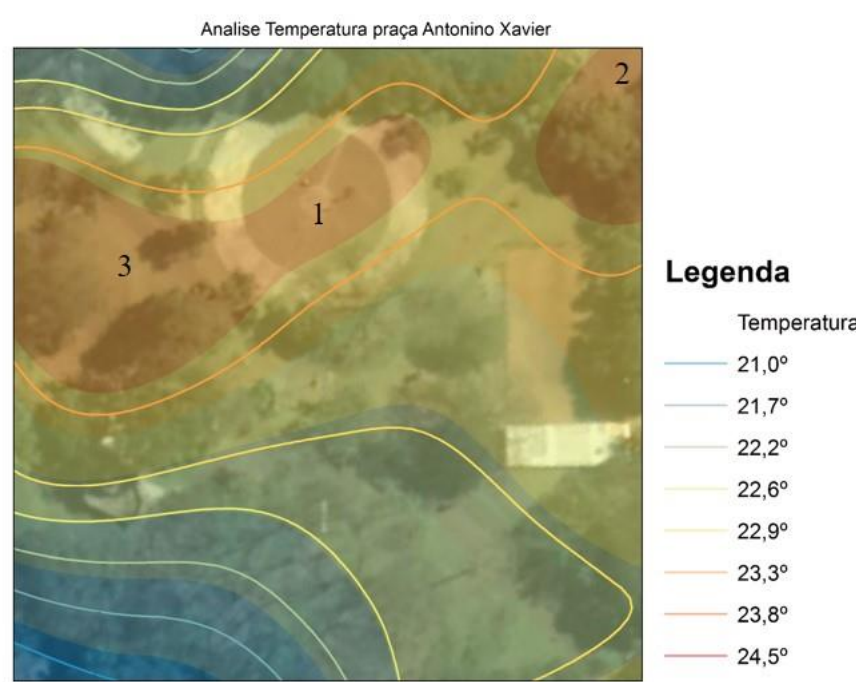

Fonte: AUTORES, 2019.

Com relação à vegetação do local, foram identificados 149 exemplares arbóreos, pertencentes a 22 espécies diferentes. No trecho 3-4, rua Salgado Marinho, existe um corredor arbóreo nas laterais do calçamento com diferentes espécies, sombreando o passeio para pedestres e, com isso, melhorando a ambiência local. Os caminhos diagonais 2-11- 3 são os que apresentam menos vegetação em seu entorno, em comparação com os trechos 1- 11- 4 (Figura 6).

Figura 6: Trecho diagonal 1-11-3, representado pelas linhas azuis, equivale ao caminho com menos vegetação em seu entorno. Já as linhas vermelhas, trecho 1-11-4, demonstram os caminhos com maior número arbóreo em suas laterais.

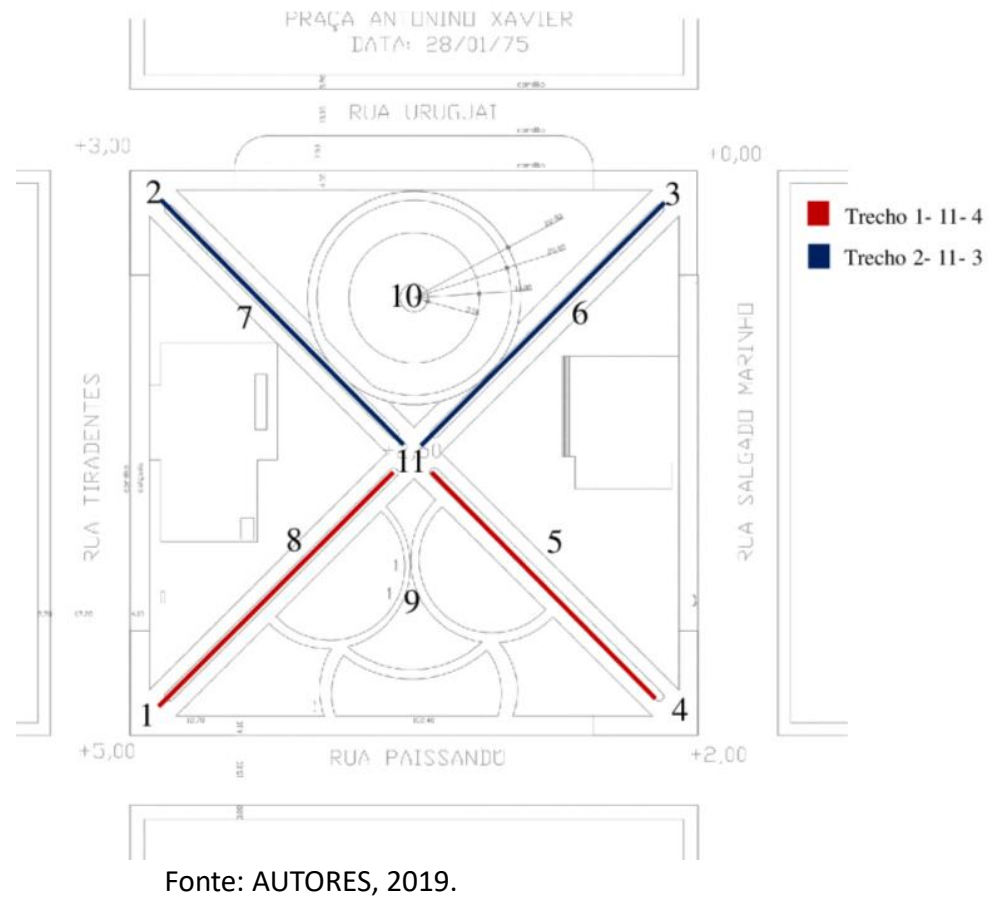

O plantio de árvores está entre as ações de adaptação das cidades as mudanças climáticas, sendo importante componente da paisagem e da ambiência com a finalidade de melhorar a 
infraestrutura verde e enfrentar o problema das "ilhas de calor" (FRANCO et al., 2013). Assim a Figura 7 representa a concentração de vegetação arbórea presente na praça, enfatiza-se que a espécie preponderante no local é o Ligustro (Ligustrum lucidum), com 36 exemplares, seguido pela Canafístula (Peltophorum dubium) com 25 exemplares e pelo Jerivá (Syagrus romanzoffiana) com 17 exemplares. Destaca-se a necessidade de manejo em relação ao Ligusto (Ligustrum lucidum) devido a característica alergênica, o que pode acentuar as doenças alérgicas nas pessoas.

Quanto a vegetação arbustiva da praça, encontram-se exemplares de azaléia (Rhododendron simsii) angiquinho (Calliandra brevipes), ave do paraíso (Strelitzia reginae), calatéia (Calateia sp.) e íris (Iris sp.), proporcionando um colorido ao ambiente. A vegetação tem grande importância na melhoria climática o que pode ser constatado na afirmação de Melo; Romanini, (2007) onde enfatiza a contribuição para regenerar o meio urbano e, consequentemente restabelecer o equilíbrio do homem com a área edificada. Nesse mesmo contexto, a vegetação contribui para preservação da qualidade do ar e para as mudanças climáticas, formando uma rede ecológica que engloba constituintes socioambientais e econômicos, diminuindo os efeitos das ilhas de calor, evitando a concentração de ar quente e gases do efeito estufa, amenizando os efeitos danosos no meio urbano (BENEDICT E MCMAHON, 2009, BUENO, XIMENES,2011, ROMERO, 2015).

Figura 7: Quantitativo da vegetação existente no local, por unidade arbórea.

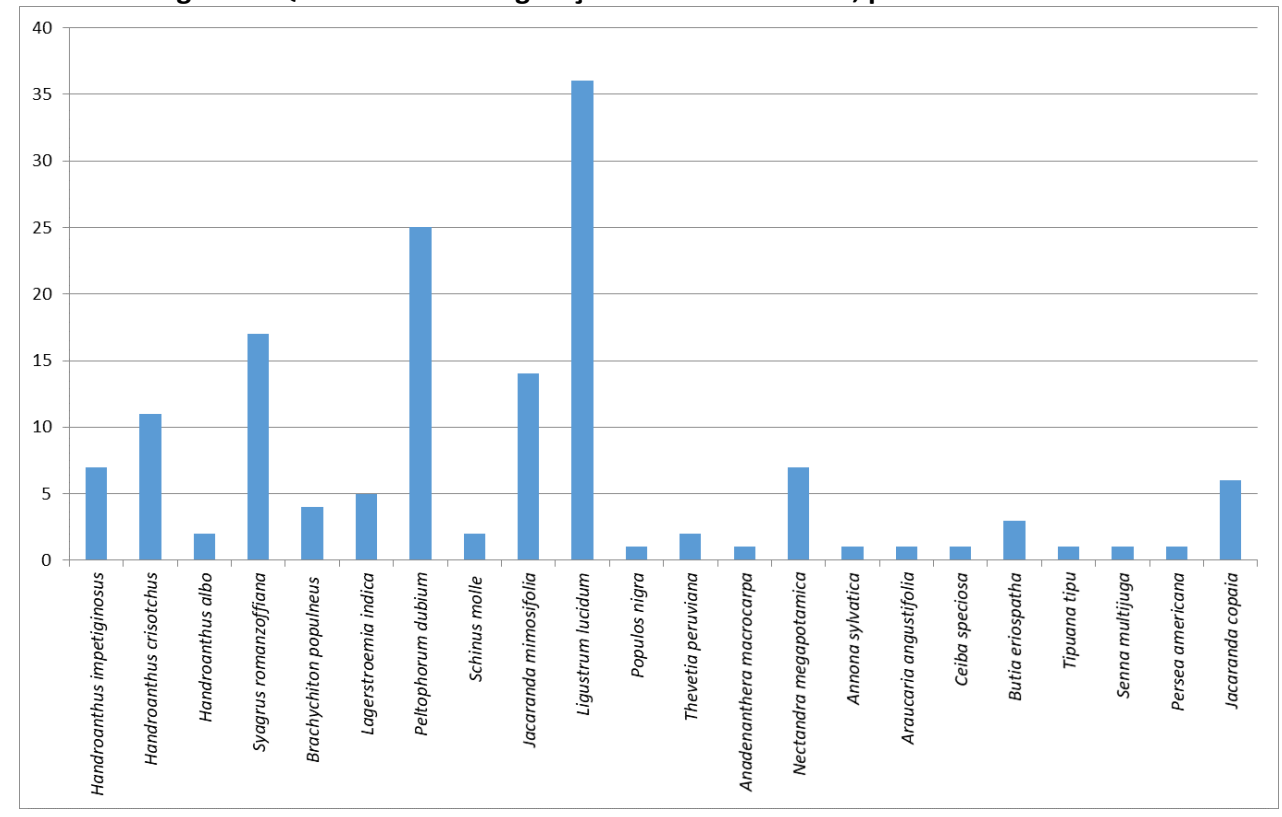

Fonte: AUTORES, 2019.

Além da coleta e análise de dados técnicos, realizou -se a aplicação de questionários aos usuários da praça, onde ao analisar as informações coletadas, verificou-se que $83,33 \%$ dos entrevistados residem no município de Passo Fundo, fator que Ihes deu condições para responder a todas as questões abordadas. Outro ponto relevante é a faixa etária do público envolvido, onde $25 \%$ dos entrevistados possui entre 20 e 30 anos, $16,66 \%$ têm entre 30 e 40 anos, $25 \%$ possui entre 40 e 50 anos, 16,66\% têm mais de 60 anos, além disso, 16,66\% não responderam. Quando questionados sobre a existência de placas informativas sobre a vegetação, as respostas foram unanimes: não existem placas explicativas sobre as espécies da praça. 
Com relação à denominação da praça - uma das perguntas de conhecimentos gerais sobre o local -, cerca $50 \%$ dos entrevistados afirma nomeá-la como "Praça do Hospital da Cidade", por estar localizada em frente à instituição de saúde. Isso demonstra como os espaços abertos públicos tornam-se um ponto de referência e possuem uma forte relação com as atividades que ocorrem no entorno.

Ao serem questionados sobre a distância em que residem da praça, $41,66 \%$ dos entrevistados afirmou morar de 2 a 4 quarteirões do local. Constata-se, portanto, que boa parte dos usuários reside na região onde ela está localizada, considerando que a pesquisa foi realizada na quartafeira dia 19 de setembro de 2018, no turno da manhã. Assim, conclui-se que os entrevistados são frequentadores assíduos da praça, por transitarem pela região diariamente. Quando indagados sobre o turno em que mais frequentam o local, a 100\% dos usuários afirmou visitar a área no período da manhã, de acordo com a Figura 8. A baixa frequência dos usuários no período da noite demonstra a falta de segurança que existe no local, fato este que está ligado diretamente com a baixa iluminação artificial do local neste período.

Um total de $75 \%$ dos questionados diz que visita ou passa pela praça no mínimo cinco vezes em sete dias. Com isso, percebe-se que a área é bastante movimentada, mesmo em dias de semana. Sobre o tempo de permanência no local, observa-se que $16,66 \%$ das pessoas entrevistadas permanece na área por no máximo uma hora. Nota-se também que grande parte de as utiliza o local apenas como rota de passagem, não usufruindo-a para momentos de lazer e contemplação.

Figura 8: Turno em que os usuários mais frequentam a praça, medido em porcentagem.

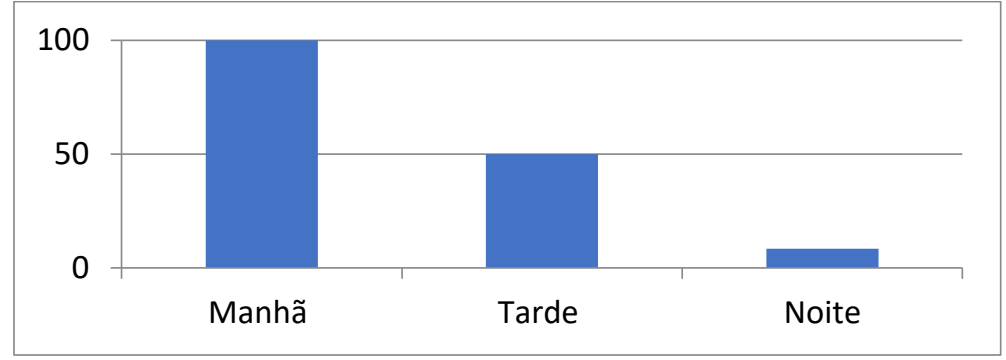

Fonte: AUTORES, 2019.

Entre as questões abordadas, uma de extrema importância para a análise baseou-se no mobiliário e espaços de lazer existentes na área. Dentre as opções, há bancos, brinquedos, banheiros ou a utilização da praça somente como via de passagem. Constatou-se que o mobiliário mais utilizado são os bancos - citados por $58,33 \%$ dos entrevistados -, atuando como locais de descanso, contemplação e convivência. Os brinquedos aparecem em segundo lugar, visto que o local possui um playground infantil bem conservado e composto por diversas opções de atividades. As pessoas que utilizam apenas o local como passagem acabam não usufruindo do mobiliário disponível no mesmo.

Quanto ao visual da praça, 83,33\% dos entrevistados consideram a paisagem agradável. Quando questionados a maioria dos usuários enfatizou a importância da arborização no composto paisagístico, comprovando que esse fator contribui não somente para ambiência climatológica do local, mas também para a sua beleza. Além disso, para algumas pessoas, a praça poderia ter mais áreas de gramado e menos áreas impermeáveis de passeio, como concreto e pedra. Para 
Melo et al. (2019) a importância do conhecimento e preservação da flora urbana permite valorizar os aspectos paisagísticos e ecológicos com a utilização, especialmente de espécies nativas, contribuindo na arborização, visando a melhoria da ambiência urbana de forma a tornar os espaços verdes mais confortáveis com influência direta na vida dos usuários da praça e entorno.

Sobre a manutenção da área, $16,66 \%$ dos usuários considera a praça um local limpo e em bom estado de conservação. Porém, algumas pessoas comentaram sobre limpeza da fossa séptica dos banheiros existentes na área da praça, que ocorre com frequência e ocasiona o escorrimento de esgoto em algumas partes dos passeios de pedestres, deixando o local com odor desagradável. Ainda sobre a limpeza do local, com relação à coleta seletiva de resíduos, $41,66 \%$ das pessoas acredita que a praça possui coleta seletiva, porém 33,33\% delas afirma que os resíduos não são recolhidos separadamente para reciclagem, deixando claro que as lixeiras, mobiliários de extrema importância, não estão preparadas para a separação correta dos resíduos.

Outro fator importante para a análise é a questão da acessibilidade. As praças são locais destinados à integração e ao lazer da população, porém, nem sempre é possível que essas áreas sejam frequentadas por todas as pessoas. Com relação a esse quesito, 58,33\% dos entrevistados acreditam que a praça possui acessibilidade. Porém, a área não pode ser considerada totalmente acessível, de acordo com a norma NBR 9050, pois, além de apresentar caminhos irregulares, os passeios não possuem piso podotátil (Figura 9).

Figura 9: Passeio de pedestres em condições irregulares e sem piso podotátil, resultando em uma praça não acessível, conforme NBR 9050.

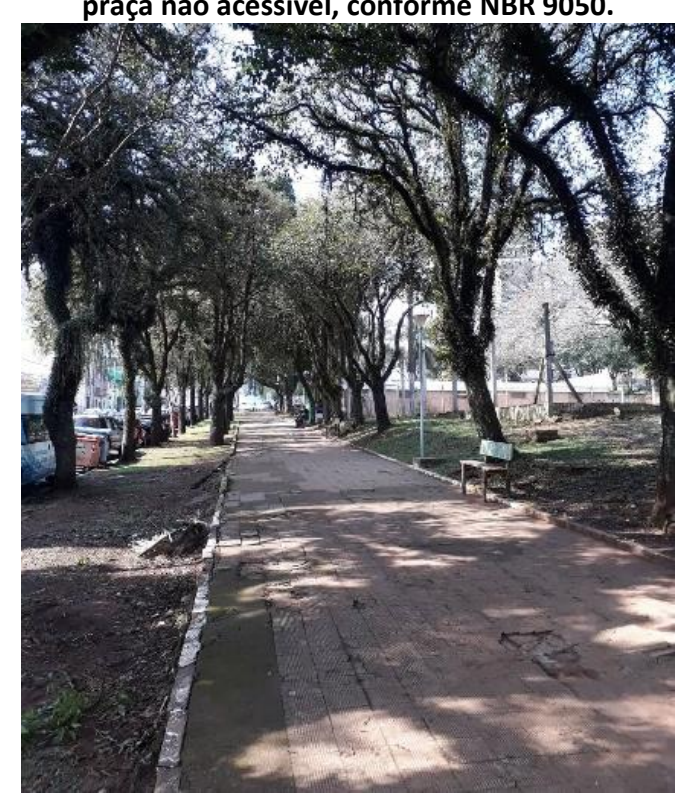

Fonte: AUTORES, 2019.

Sobre o uso da praça, nota-se que $50 \%$ visita o local com o objetivo de descanso e contemplação, seguido pela utilização do local como via de passagem e, por fim, por lazer e recreação (Figura 10).

Com relação à presença de cores na praça, 83,33\% acreditam que a área poderia ser mais colorida, apresentando maior quantidade de flores, pinturas pelos caminhos e nos bancos. 
Quanto à quantidade de vegetação existente, para $66,66 \%$, a praça possui árvores suficientes, porém, segundo eles, há falta de manutenção arbórea. Já sobre as áreas sombreadas, 91,66\% dos entrevistados acreditam que a praça possui muitos locais com sombra e estes atendem as necessidades do local. Quanto ao mobiliário, grande número dos entrevistados entende que a praça possui luminárias suficientes para abranger toda a área.

Figura 10: Objetivos dos usuários ao utilizarem a praça.

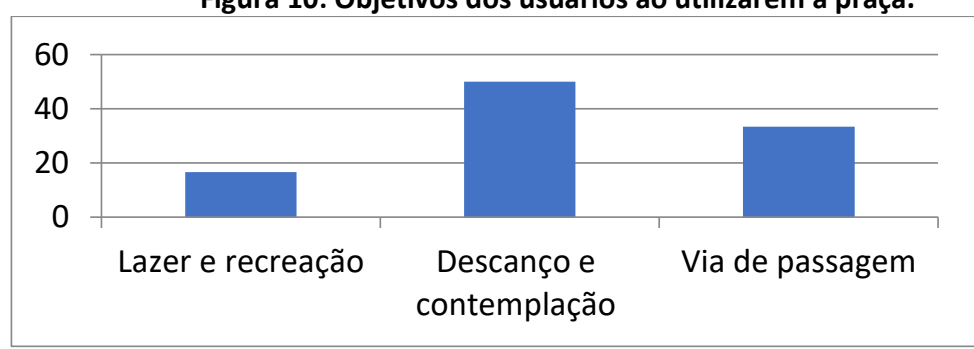

Fonte: AUTORES, 2019.

$\mathrm{Na}$ infraestrutura, a maioria das pessoas acredita que a área possui calçamento necessário para locomoção, porém, há a falta de manutenção dos passeios e atendimento a norma NBR 9050. Demonstrando a necessidade de intervenção pelo poder público para resolver os problemas de acessibilidade universal.

A pesquisa pode servir de ancoragem para futuros projetos de intervenção que visem o melhoramento da infraestrutura do local, além de evidenciar a importância das áreas verdes com massas arbóreas nos centros urbanos para a melhoria da ambiência e conforto ambiental.

\section{CONCLUSÕES}

A partir desta pesquisa constatou-se que, mesmo em espaços localizados próximos a maciços vegetativos, existem ilhas de calor na Praça Antonino Xavier. Nas áreas que apresentam um maior número de vegetações, percebe-se que as temperaturas são inferiores, deixando o ambiente ameno. Com isso, fica evidente a importância das árvores nos espaços urbanos, visto que, além de melhorarem as condições climáticas das áreas, auxiliam, também, na qualidade do ar, contribuindo para a sustentabilidade ambiental e qualificando os espaços.

Nota-se, ainda, que a praça conta com uma variedade de espécies arbóreas, em especial o Ligustro (Ligustrum lucidum) - árvore muito utilizada na arborização urbana, por ser resistente à poda e, com isso, capaz de projetar um denso sombreamento durante o ano todo, porém apresenta princípios alergênicos. Sobre os estudos da influência do entorno no sombreamento da praça, concluiu-se que, no inverno, principalmente no mês de junho, o entorno influencia diretamente na qualidade climática da área, pois gera sombreamento em quase todos os ambientes, tornando a área um local frio e úmido, impróprio para realizar atividades de lazer e contemplação. Já no mês de setembro, os edifícios deixam de projetar sombra em excesso na praça, fazendo com que o local apresente melhores temperaturas e condições de uso mais agradável contribuindo com a ambiência urbana.

Em relação aos usos, concluiu-se que o mobiliário mais utilizado pelos frequentadores do local são os bancos, os quais, necessitam de melhorias quanto a sua estrutura e acabamento. Além disso, o playground infantil apareceu como a segunda área mais aproveitada, pois está 
localizado em um local bem sombreado e apresenta boas condições. Outro ponto importante, é o fato de que grande parte dos usuários considera que a praça possui visuais agradáveis, apesar de necessitar de manutenção em alguns pontos. A percepção dos usuários evidencia a necessidade de pinturas e flores para maior colorido na paisagem.

Por fim, por meio deste estudo, concluiu-se que existem muitos fatores que podem influenciar na climatologia urbana, como o gabarito do entorno, a trajetória solar, a época do ano e a presença ou não de maciços vegetativos na área. Percebeu-se, também, que o crescimento desordenado das grandes cidades tem sido um fator relevante na falta de planejamento urbano. Com a análise solar, observou-se que, especialmente no inverno - tradicionalmente rigoroso na região sul do país -, a área deveria receber insolação direta, proporcionando aos seus usuários espaços de lazer agradáveis e menos úmidos, de modo que possa ser utilizada em todas as estações do ano.

\section{REFERÊNCIAS BIBLIOGRÁFICAS}

AMORIM, Margarete Cristiane de Costa Trindade. ILHAS DE CALOR EM BIRIGUI/SP. Revista Brasileira de Climatologia, Curitiba, v. 1, n. 1, p.121-130, 2005.

BENEDICT, M. A.; MCMAHON, T. Green Infrastructure: Linking Landscapes and Communities. Washington, DC; Island Press, 2009.

BUENO, E. S.; XIMENES, D.S.S. A importância da infraestrutura verde no desenho ambiental: estudo da área da cidade universitária e instituto Butantã. REVISTA LABVERDE, São Paulo, n.3, p. 128-154, 2011.

DUARTE, D. H. S. Padrões de ocupação do solo e microclimas urbanos na região de clima tropical continental. Tese (Doutorado em Arquitetura). Faculdade de Arquitetura e Urbanismo da Universidade de São Paulo. São Paulo, 2000.

EPA, U. S.; Environmental Protection Agency. Reducing Urban Heat Islands: Compendium of Strategies - Urban Heat Island Basics. 2008. Disponível em: <http://www.epa.gov/heatisland.> Acesso em 18 de junho de 2019.

FRANCO, F. M.; NOGUEIRA, M. C.; MUSIS, C. R. D.; DURANTE, L. C.; NOGUEIRA, J. S. Atributos bioclimáticos urbanos uma análise sobre o ponto de vista qualitativo. Revista Monografias Ambientais. REMOA/UFSM. v 10, no 10, p. 2270 - 2277 Santa Maria, 2012. Disponível em:

<https://www1.ufmt.br/ufmt/unidade/userfiles/publicacoes/91452b48cd71d8762b0c9eccea4ce9f4.pdf>. Acesso em 8 mai. 2019.

FRANCO, M.; OSSE, V. C.; MINKS, V. Infraestrutura verde para as mudanças climáticas no C40. Revista LABVERDE, n. 6, p. 220-235, 20 jun. 2013.

GARTLAND, Lisa. Heat Islands: Understanding and mitigating heat in urban areas. London: Earthscan, 2008. 208 p.

GEHL, J. Life Between Buildings: Using Public Space. edição revisada. Washington: Island Press, 1987, 2011.

LOMBARDO, M.A. Ilhas de Calor nas Metrópoles: o exemplo de São Paulo. São Paulo: HUCITEC, 1985. 244 p.

MELO, E.F.R.Q.; CARASEK, M.; MELO, R.H.R.Q. Ecologia Urbana: Vegetação arbórea de um município de pequeno porte. Revista Nacional de Gerenciamento de Cidades, [S.I.], v. 7, n. 48, ago. 2019. ISSN 2318-8472. Disponível em: <http://www.amigosdanatureza.org.br/publicacoes/index.php/gerenciamento_de_cidades/article/view/2102>. Acesso em: 20 Out. 2019. doi:http://dx.doi.org/10.17271/2318847274820192102.

MELO, R. H. R. Q.; MELO, R. H. R. Q.; MELO, E. F. R. Q. A influência da tipologia construtiva na ambiência urbana: ilhas de calor. Revista Nacional de Gerenciamento de Cidade. v 05, $n^{\circ} 33$, p. 114, 2017. Disponível em: < http://www.amigosdanatureza.org.br/publicacoes/index.php/gerenciamento_de_cidades/article/view/1608/1595> . Acesso em 8 mai. 2019. 
MELO, E. F. R. Q.; ROMANINI, A. A gestão da arborização urbana na cidade de Passo Fundo/RS. Revista SBAU, Piracicaba, v. 2, n. 1p. 1-16, 2007.

OKE, T. R. Boundary Layer climates. 2 ed. London: Methuen, 1987.

PINHEIRO, J. de Q.; GÜNTER, H. Métodos de pesquisa nos estudos pessoa-ambiente. São Paulo: Casa do Psicólogo, 2008.

ROMERO, M. A. B. Princípios bioclimáticos para o desenho urbano. Editora: CopyMarket.com, 2000. Disponível em: $<$ http://airesfernandes.weebly.com/uploads/5/1/6/5/5165255/princpios_bioclimticos_para_o_desenho_urbano.pd f > Acesso em 08 mai. 2019. $226 \mathrm{p}$.

. A arquitetura bioclimática do espaço público. 4 ạ reimpressão, Brasília: Editora Universidade de Brasília, 2015.

SANTAMOURIS, M. Using cool pavements as a mitigation strategy to fight urban heat island - A review of the actual developments. Renewable and Sustainable Energy Reviews, 26, pp. 224-240, 2013.

SCHUTZER, J. G. Cidade e meio ambiente: categorias para o estudo das relações entre a cidade e o meio ambiente. São Paulo: Edusp, 2012.

STEWART, I.; OKE, T. Local climate zones for urban temperature studies. American Meteorological Society, v.93, p. 1879-1900, 2012. 